\title{
A Research on House Rent in Coimbatore
}

\author{
C.Sunitha, Subasri K, Thenmozhi M
}

\begin{abstract}
In today's world People search for rentals with various concerns such as budget, size and many more. The rental cost of a house will be based on various factors like the locality of the house, size, no of rooms, individual house, water facility etc. The increase in house rent in a particular area depends on the market trend and the development of the locality. The rentals of various areas in Coimbatore have been collected and recorded to analyze the rental differences within the city. $R$ is a product situation and code for performing basic and complex factual tasks on information. It likewise has wide includes for designs. Both these make it in a perfect world reasonable for logical and research registering. $R$ has extraordinary plotting abilities and this structures a basic piece of information analysis. The inquire about the rentals of house rent have been performed by utilizing $\boldsymbol{R}$.
\end{abstract}

Keywords-Area, Cost, House, Locality, R, Rental, Market strategy.

\section{INTRODUCTION}

In today's trend huge amount of knowledge have been invested in data mining, deep learning, natural language processing ,Machine learning, text mining etc..There are various challenges in Using automated data mining algorithms to discover knowledge from natural language texts but still it offers unique possibilities. The information could be stored either as text,csv format etc.Preferably it will be saved in natural text format. This text will be easy to interpret for humans but not for computers. For computers, it will be a tough task to acquire meaning or information from that data. But still, computer have an important advantage over humans (i.e.) the computer power, which means that computers can find patterns, which are nontrivial recurrences, inside information quicker and more exact than their human partner, however this must be done if the structure of the information is known. $\mathrm{R}$ is the most flexible statistical programming language. It has an environment that is Open Source and freely accessible for all probable operating systems. The flexibility of $\mathrm{R}$ could not match with any other statistics program, as its objectoriented programming language permits for the creation of functions that perform customized procedures and/or the automation of tasks that are usually completed. There is a need to analyse the efficient house rent pricing for Common people with Coimbatore. This analysis efficiently analyses previous market trends, price ranges and the development of the locality and also it helps in understanding the current market using R. This analysis uses data mining algorithm along with $\mathrm{R}$ Language to analyse the pricing of the houses

\section{DESIGN/METHODOLOGY/APPROACH}

A survey was conducted with a questionnaire set which included the information of house rent of individual houses in and around their locality in and around Coimbatore which includes hope college, Gandipuram, Sitra, KovaiPudur etc.

\section{Findings}

The study finds a significant relationship between the value of the house and the locality. The value of the house is also related with the type of house they are interested in. There are various types of houses with various specifications like no of rooms, water facility, maintenance, lift facility etc..The rent of the houses in directly proportional to the facilities which are there in the house and also the familiarity of the locality.

\section{Research limitations/implications}

Data mining helps in finding of useful, valid, unpredicted, and comprehensible knowledge from data. One of the notable unique issues in data mining is size. $\mathrm{R}$ has limitations with management of enormous datasets because all computations are carried out in the main memory of the computer. This does not mean that we will not be able to handle these problems. Taking advantage of the highly flexible database interfaces which are available in $\mathrm{R}$, data mining on large problems can be performed. Data mining is widely used in various domains, such as retail, finance, telecommunication and social media. The primary methods for information mining incorporate order and forecast, bunching, exception location, affiliation rules, grouping examination, time arrangement investigation and content mining, and furthermore some new systems, for example, interpersonal organization examination and supposition examination.

This results suggests that the analysis is purely based on the

respondents and may have split opinion on the existing anecdotal evidence that participants express their view about the rentals. The Opinion diversity on some factors will also affect the value and so accuracy should be built to prevent the variation.

\section{Originality/value}

The study makes an important contribution in analyzing the ground rent on houses in and around Coimbatore based on the data collected. This could also be extended to predict the future rents of residential houses in a particular locality 


\section{DATASET (HOUSE RENT IN COIMBATORE)}

The below mentioned in the dataset on rent of individual houses in different areas in Coimbatore.eg, The rent of Gandipuram's being calculated by taking mean of the house rent of in and around Gandipuram area for a particular year period. Like wise the rent is calculated for all the areas. The mean is calculated by the formula

\begin{tabular}{|c|c|c|c|c|}
\hline [2] Place & [3] Year & [4] $1 \mathrm{BHK}$ & [5] $2 \mathrm{BHK}$ & $\begin{array}{ll}\text { [6] } & 3 \text { BHK } \\
\text { [7] } & \end{array}$ \\
\hline \multirow[t]{5}{*}{ Gandhipuram } & [9] 1990-2000 & [10] 1000 & [11] 1800 & [12] 2500 \\
\hline & [13] 2001-2005 & [14] 1500 & [15] 2300 & [16] 3000 \\
\hline & [17] 2006-2010 & [18] 2500 & [19] 3500 & [20] 4500 \\
\hline & [21] 2011-2015 & [22] 4500 & [23] 5000 & [24] 8000 \\
\hline & [25] 2015-2019 & {$[26] 7500$} & [27] 12000 & [28] 15000 \\
\hline \multirow[t]{5}{*}{ [29] Ramanathapuram } & [30] 1990-2000 & [31] 1500 & [32] 1750 & [33] 2300 \\
\hline & [34] 2001-2005 & [35] 2000 & [36] 2500 & [37] 3000 \\
\hline & [38] 2006-2010 & [39] 3000 & [40] 3500 & [41] 5000 \\
\hline & [42] 2011-2015 & [43] 3800 & [44] 5000 & [45] 8000 \\
\hline & [46] 2015-2019 & [47] 8000 & [48] 14000 & [49] 20000 \\
\hline \multirow[t]{5}{*}{ [50] Singanallur } & [51] $1990-2000$ & [52] 1500 & [53] 1700 & [54] 2300 \\
\hline & [55] 2001-2005 & [56] 2200 & [57] 2800 & [58] 3400 \\
\hline & [59] 2006-2010 & {$[60] 2500$} & [61] 3000 & [62] 4000 \\
\hline & [63] 2011-2015 & [64] 4500 & [65] 6000 & [66] 10000 \\
\hline & [67] 2015-2019 & {$[68] 7500$} & [69] 15000 & [70] 21000 \\
\hline \multirow{5}{*}{ [71] Peelamedu } & [72] 1990-2000 & [73] 1500 & [74] 1800 & [75] 2300 \\
\hline & [76] 2001-2005 & [77] 1800 & [78] 2300 & [79] 3000 \\
\hline & [80] 2006-2010 & {$[81] 2500$} & [82] 3000 & [83] 4000 \\
\hline & [84] 2011-2015 & [85] 3500 & [86] 5000 & [87] 7000 \\
\hline & [88] 2015-2019 & [89] 9000 & [90] 15000 & [91] 20000 \\
\hline \multirow[t]{5}{*}{ [92] Saravanampatti } & [93] 1990-2000 & [94] 500 & [95] 800 & [96] 1200 \\
\hline & [97] 2001-2005 & [98] 800 & [99] 1200 & [100]1500 \\
\hline & [101] 2006-2010 & {$[102] 1500$} & [103]2500 & [104]3500 \\
\hline & [105] 2011-2015 & {$[106] 2800$} & [107] 3500 & [108]5000 \\
\hline & [109] 2015-2019 & {$[110] 3500$} & {$[111] 7500$} & [112] 13000 \\
\hline \multirow[t]{5}{*}{ [113] Saibaba Colony } & {$[114] 1990-2000$} & {$[115] 500$} & {$[116] 700$} & [117] 1000 \\
\hline & [118] 2001-2005 & [119] 800 & {$[120] 1200$} & [121] 1800 \\
\hline & [122] 2006-2010 & [123] 1500 & {$[124] 2000$} & [125]2500 \\
\hline & [126] 2011-2015 & {$[127] 2500$} & {$[128] 3500$} & [129] 7000 \\
\hline & [130] 2015-2019 & {$[131] 8000$} & {$[132] 12000$} & [133] 25000 \\
\hline \multirow[t]{5}{*}{ [134] Thudiyalur } & [135] 1990-2000 & {$[136] 500$} & {$[137] 850$} & [138] 1200 \\
\hline & [139] 2001-2005 & {$[140] 800$} & [141] 1200 & [142] 1800 \\
\hline & [143] 2006-2010 & {$[144] 1500$} & {$[145] 2500$} & [146]3500 \\
\hline & [147] 2011-2015 & {$[148] 3500$} & [149]5000 & {$[150] 6500$} \\
\hline & [151] 2015-2019 & {$[152] 6000$} & [153]12000 & [154] 16000 \\
\hline \multirow[t]{5}{*}{ [155] Sulur } & [156] 1990-2000 & {$[157] 300$} & [158] 500 & [159] 1000 \\
\hline & [160] 2001-2005 & [161]500 & {$[162] 800$} & [163]1500 \\
\hline & [164] 2006-2010 & {$[165] 1000$} & {$[166] 1500$} & [167] 3000 \\
\hline & [168] 2011-2015 & [169] 2000 & {$[170] 3000$} & [171]5000 \\
\hline & [172] 2015-2019 & {$[173] 8500$} & [174]11000 & [175] 15000 \\
\hline \multirow[t]{5}{*}{ [176] Vadavalli } & [177] 1990-2000 & {$[178] 1000$} & [179] 1500 & [180] 1800 \\
\hline & [181] 2001-2005 & [182] 1500 & [183] 2000 & [184]2500 \\
\hline & [185] 2006-2010 & {$[186] 2000$} & {$[187] 2500$} & [188]4000 \\
\hline & [189] 2011-2015 & {$[190] 2500$} & {$[191] 3500$} & {$[192] 7000$} \\
\hline & [193] 2015-2019 & {$[194] 8500$} & [195] 15000 & [196] 25000 \\
\hline
\end{tabular}

data frame can be created using the pre defined function data. Frame() within which we can pass the vector values.

The data frame can be saved in a variable. Thedata frame could also be named using the function names(variable name)<- names within a vector; The data's can be written in to a CSV file by using the function write.csv("filename").In the same way, the data's could be read from csv using the function read.csv("filename"). The csv file read could be saved in a variable name. If we print the variable name, the data's in the csv file will be printed.

$>$ var $1<-$ sample $(5)$

$>$ var2<-var $1 / 10$ a data frame into a csv file and also reading the data's from the file into R. At first, we create three vectors, an integer vector, a numeric (real) vector and a character vector. The 
$>$ var3<-

c("R","and","DataMining","Examples","CaseStudies")

$>$ df1<-data.frame(var1,var2,var3)

$>$ names(df1)<-c("Var.Int","Var.Num","Var.Char")

$>$ write.csv(df1,"./data/mydatafile3.csv",row.names=FAL

SE)

$>$ df2<-read.csv("./data/mydatafile3.csv")

$>\operatorname{print}(\mathrm{df} 2)$

$\begin{array}{lll} & \text { Var.Int } & \text { Var.Num } \\ 1 & 5 & 0.5 \\ 2 & 6 & 0.6 \\ 3 & 7 & 0.7 \\ 4 & 8 & 0.8 \\ 5 & 9 & 0.9\end{array}$

\section{DATA ANALYSIS USING R}

\section{Individual Analysis}

The data set in csv file have been imported to $\mathrm{R}$ and the analysis was done by preparing various charts to analyse the house rent in various areas

Data analysis of House Rent In Coimbatore in various areas From 1990 - 2019

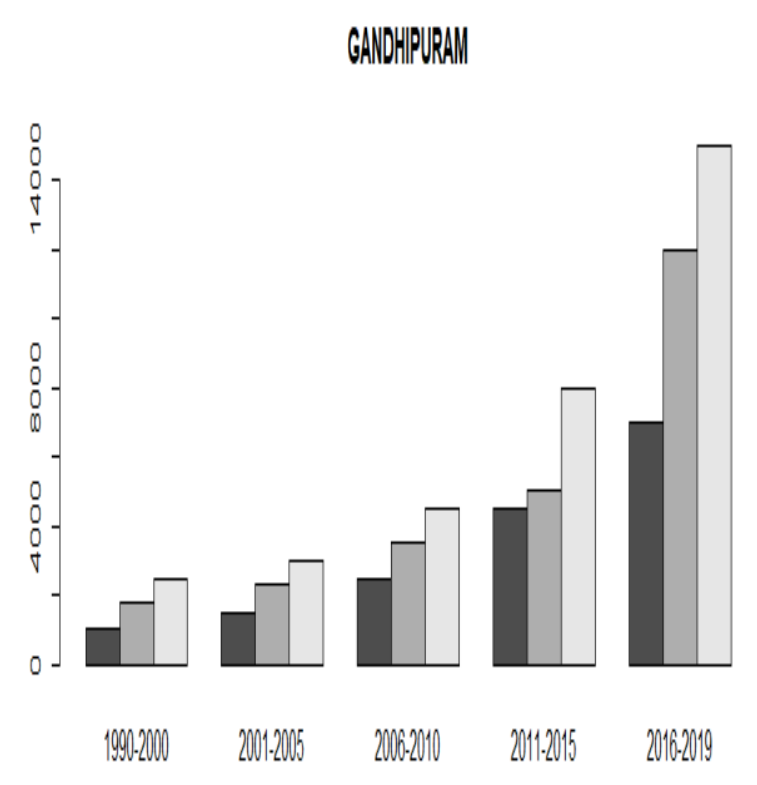

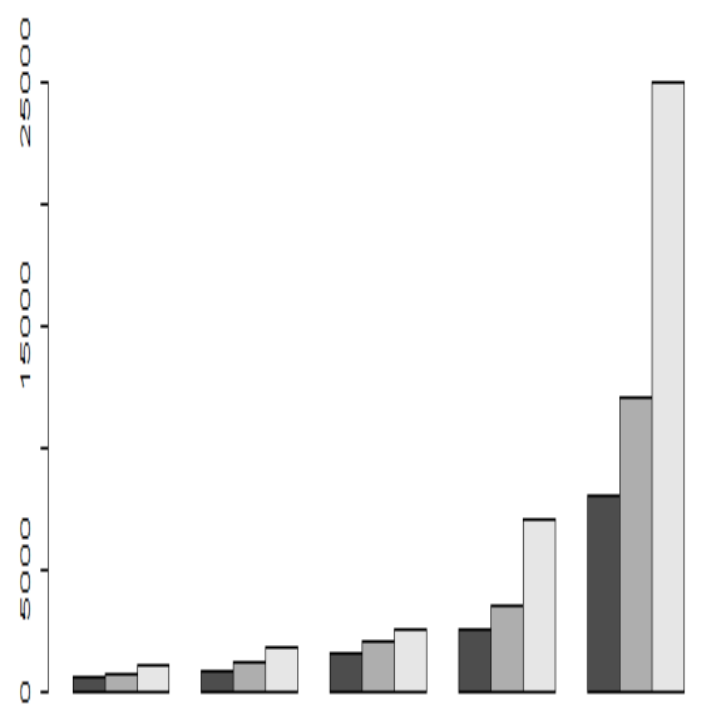

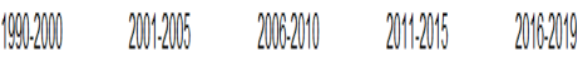


SHANAAMANATTIT

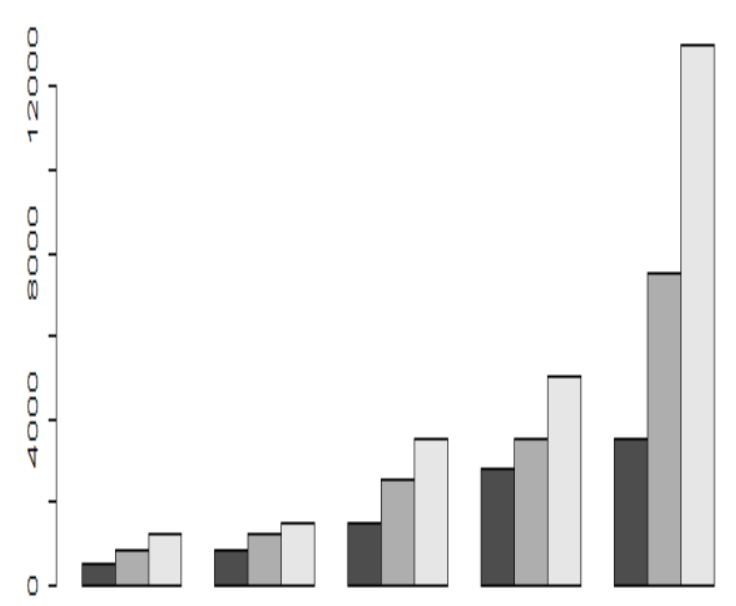

1990.2000 2001.2005 2006-2010 2011-2015 2010.2019

SNGANALLVR

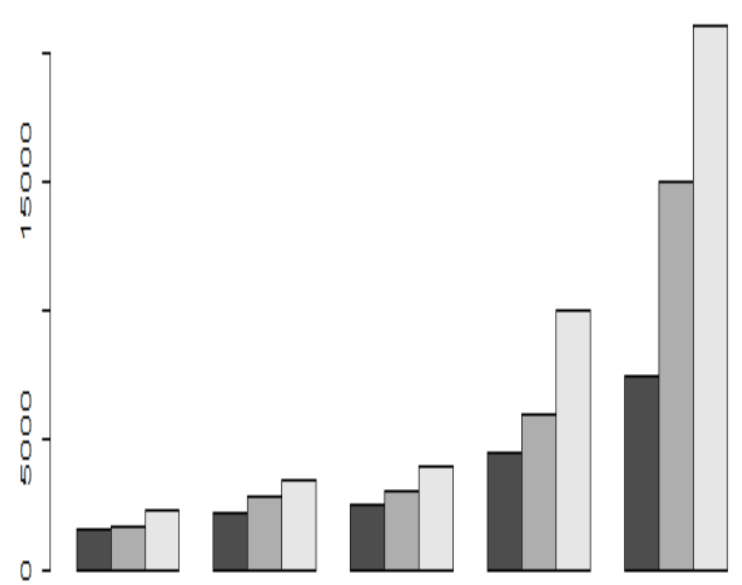

1902-2001 2002005 2002010 20112015 2016-219
THUDYALVR

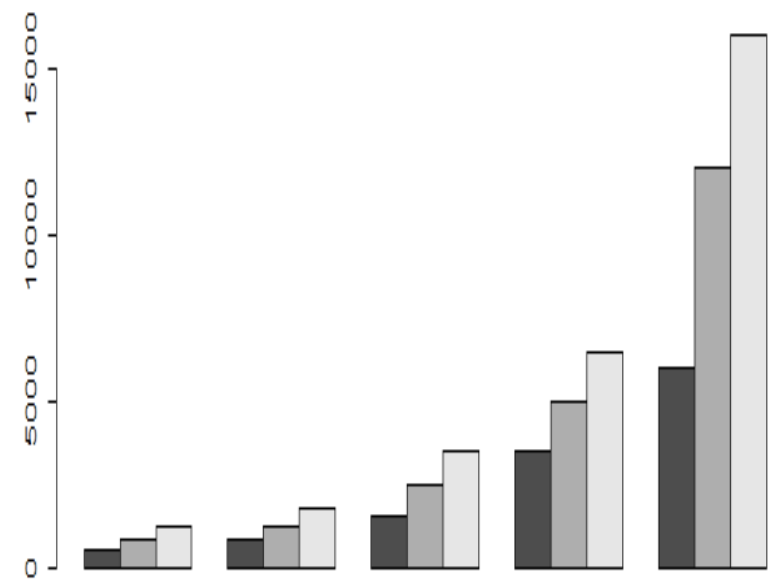

1990-2000 2001-2005 2006-2010 2011-2015 2016-2019
VADANALII
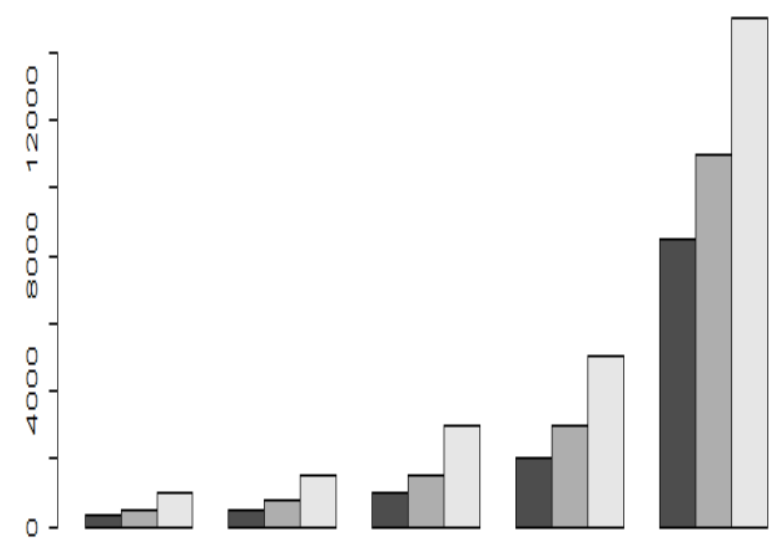

1990-2000

$2001 \cdot 2005$

2000-2010 2011.2015

$2016-2019$ 

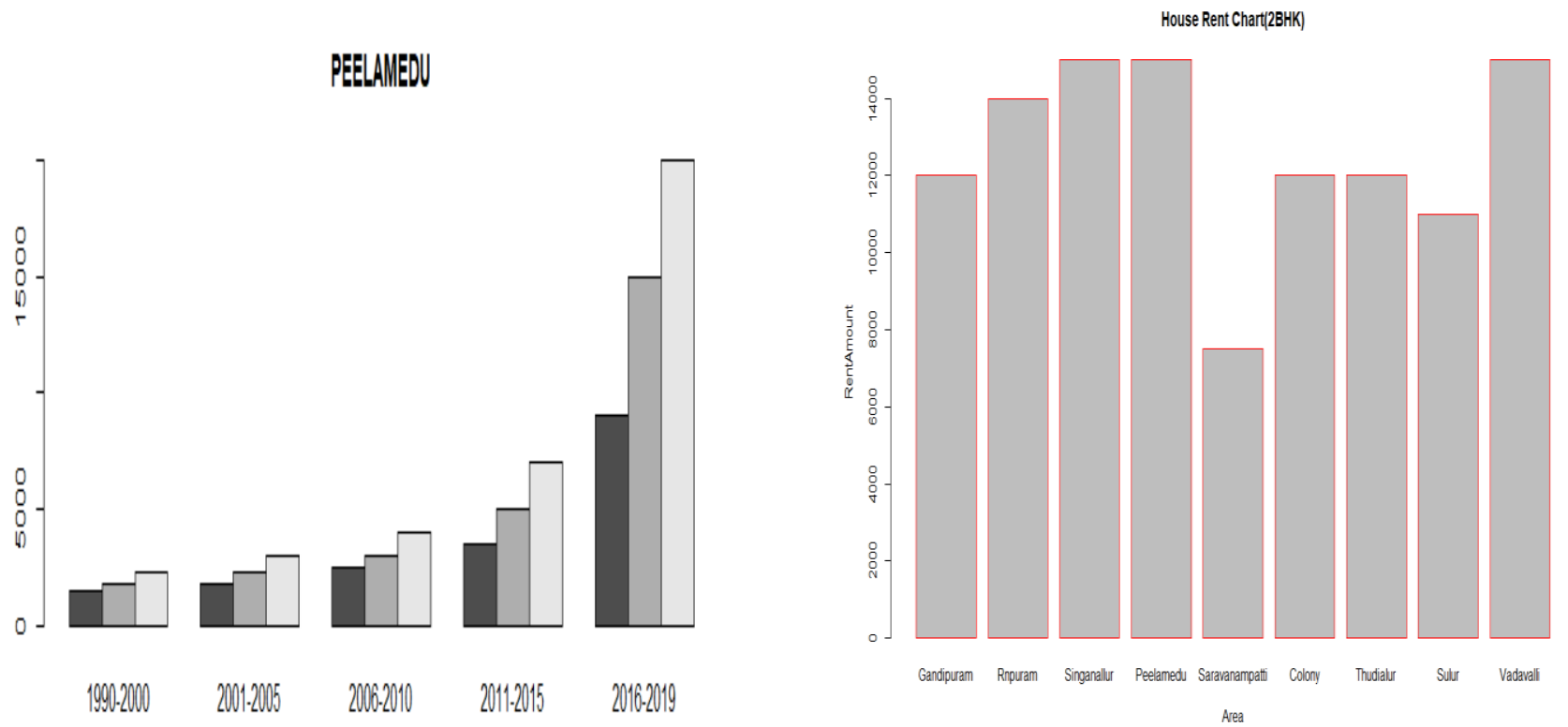

\section{Comparative Analysis}

The house rent for various areas as per BHK count as in 2019 has been analyzed with the help of chart
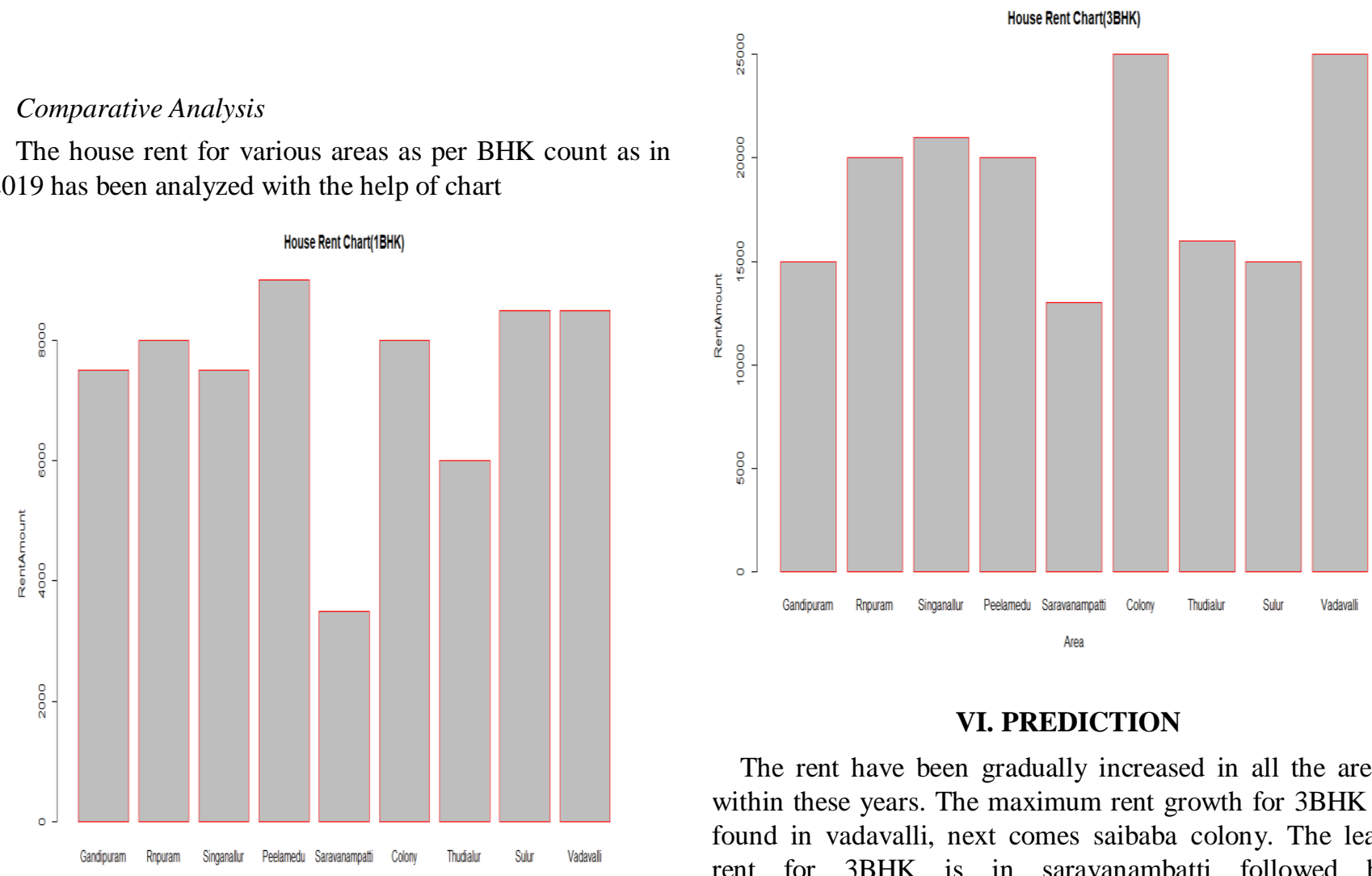

\section{PREDICTION}

The rent have been gradually increased in all the areas within these years. The maximum rent growth for $3 \mathrm{BHK}$ is found in vadavalli, next comes saibaba colony. The least rent for $3 \mathrm{BHK}$ is in saravanambatti followed by sulur.Vadavalli have incurred a major growth within these time period.

When it comes to $2 \mathrm{bhk}$, the rent is maximum in singanallur, vadavalli and peelamedu. The least rent is in Saravanambatti .Based on the house rent, the area`s growth could be predicted

\section{CONCLUSION}

The rent of the house grows based on the economy and the growth of the area, When the house rent increases

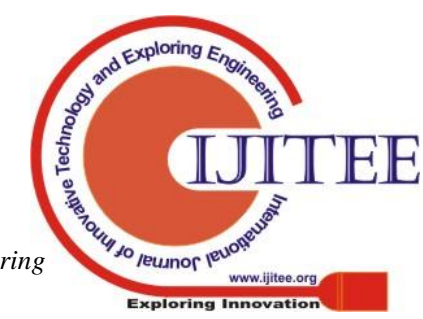


ununiformly, it means that the area have incurred a major growth. The house rent analysis have been made with $\mathrm{R}$ software and the result have led to various analysis. The house rent within Coimbatore have been analyzed. Peelamedu, saibaba colony and Vadavalli is considered as the most growing areas

\section{REFERENCES}

1. Analyzing Internet $\mathrm{DNS}(\mathrm{SEC})$ traffic with $\mathrm{R}$ for resolving platform optimization Emmanuel Herbert, Daniel Migault, Stephane Senecal, Stanislas Francfort and Maryline Laurent .

2. Angel, S. (2000). Housing Policy Matters: A Global Analysis. New York: Oxford University Press.

3. D'amika, K. (2008). Trends in GDP: The Housing Bust Continues, Net Exports Surge. American Institute for Economic Research. Retrieved August 8, 2009 from http://www.aier.org/research/commentaries/453-trendsin-gdp

4. C. Y. Lin, M. Wu, J. A. Bloom, I. J. Cox, and M. Miller, "Rotation, scale, and translation resilient public watermarking for images," IEEE Trans. Image Process., vol. 10, no. 5, pp. 767-782, May 2001.

5. Azzalini and A. W. Bowman. A look at some data on the Old Faithful geyser. Applied Statistics, 39:357-365, 1990. Cynthia A. Brewer. Color use guidelines for mapping and visualization. In A.M. MacEachren and D.R.F. Taylor, editors, Visualization in Modern Cartography, pages 123-147. Elsevier Science, 1994a. Cynthia A. Brewer. Guidelines for use of the perceptual dimensions of color for mapping and visualization. In Color Hard Copy and Graphic Arts III, Proceedings of the International Society for Optical Engineering (SPIE), San Jose, volume 2171, pages 54-63, 1994b.

6. Han, J. and Kamber, M., "Data Mining: Concepts and Techniques", Academic Press, ISBN 1- 55860-489-8.

7. https://www.researchgate.net/journal/17538270_Internati onal_journal_of_housing_markets_and_analysis

8. http://www.sthda.com/english/wiki/r-built-in-data-sets 